Полтавская Юлия Олеговна, к.т.Н., доцент, Ангарский государственный технический университет, e-mail: juliapoltavskaya@mail.ru

ОПРЕДЕЛЕНИЕ ОЧЕРЕДНОСТИ ОБСЛУЖИВАНИЯ ПОДВИЖНОГО СОСТАВА В ТРАНСПОРТНЫХ УЗЛАХ НА ОСНОВЕ КРИТЕРИЯ ОПТИМАЛЬНОСТИ

\title{
DETERMINATION ROUND OF VEHICLES SERVICE IN FREIGHT TRANSPORT HUBS ON THE CRITERION OPTIMITY
}

\begin{abstract}
Аннотация. В статье рассмотрена методика определения очередности обслуживания на основе критерия оптимальности, что позволит сократить время ожидания погрузоразгрузочных работ подвижного состава. Модель очередности обслуживания используется для описания скоординированного процесса транспортировки. Приведенный численный эксперимент отражает обоснованность модели и алгоритма.
\end{abstract}

Ключевые слова: транспортный узел, очередность обслуживания, погрузоразгрузочные работы, критерий оптимальности.

Abstract. The article describes the methodology for determining the sequence of services based on the criterion of optimality. This approach reduces the waiting time for loading and unloading of rolling stock. The service priority model is used to describe a coordinated transportation process. The given numerical experiment reflects the validity of the model and algorithm.

Keywords: transport hub, priority of service, loading and unloading, criterion optimity.

Характерной чертой транспортной отрасли является гибкость и способность реагировать на меняющиеся потребности клиентов, что приводит к увеличению товарооборота и повышению конкурентоспособности отдельно рассматриваемого предприятия. Эта тенденция прослеживается не только в региональных транспортных сетях, но и в международных и мультимодальных перевозках, которые также учитывают ряд внешних фракторов, влияющих на реализацию процесса. В связи с этим у компаний возникает потребность в применении гибких методов планирования всей цепи поставок, в которой транспорт играет решающую роль. Поэтому важно найти и использовать соответствующие инструменты для оценки эффективности транспортных процессов и снижения стоимостных затрат на доставку товара до конечного потребителя.

Процесс перевозки представляет собой комплекс операций, выполняемых в особом порядке в отношении перемещения грузов различными видами транспорта. Для интеграции различных видов транспорта играет ключевую роль стандартизированное техническое взаимодействие, которое предполагает унификацию подвижного состава, контейнеров, погрузочных машин и механизмов, фронтов погрузки и выгрузки, складских помещений; согласование параметров технических средств транспорта [1, 2]. Данный процесс может быть реализован в транспортных узлах (ТУ), которые представляют собой пространство, где происходит перевалка грузов с одного транспортного средства на дру- 
гое, или между видами транспорта. Грузовые транспортные узлы включают подъездные пути сообщения, подвижной состав различных видов транспорта, погрузо-разгрузочные механизмы, склады и их оборудование, и вспомогательные объекты производственной инфраструктуры (административные здания и сооружения) (рисунок 1). От уровня технического оснащения и организации работы транспортного узла зависит скорость перевалки грузов и оптимизация функционирования взаимодействующих видов транспорта.
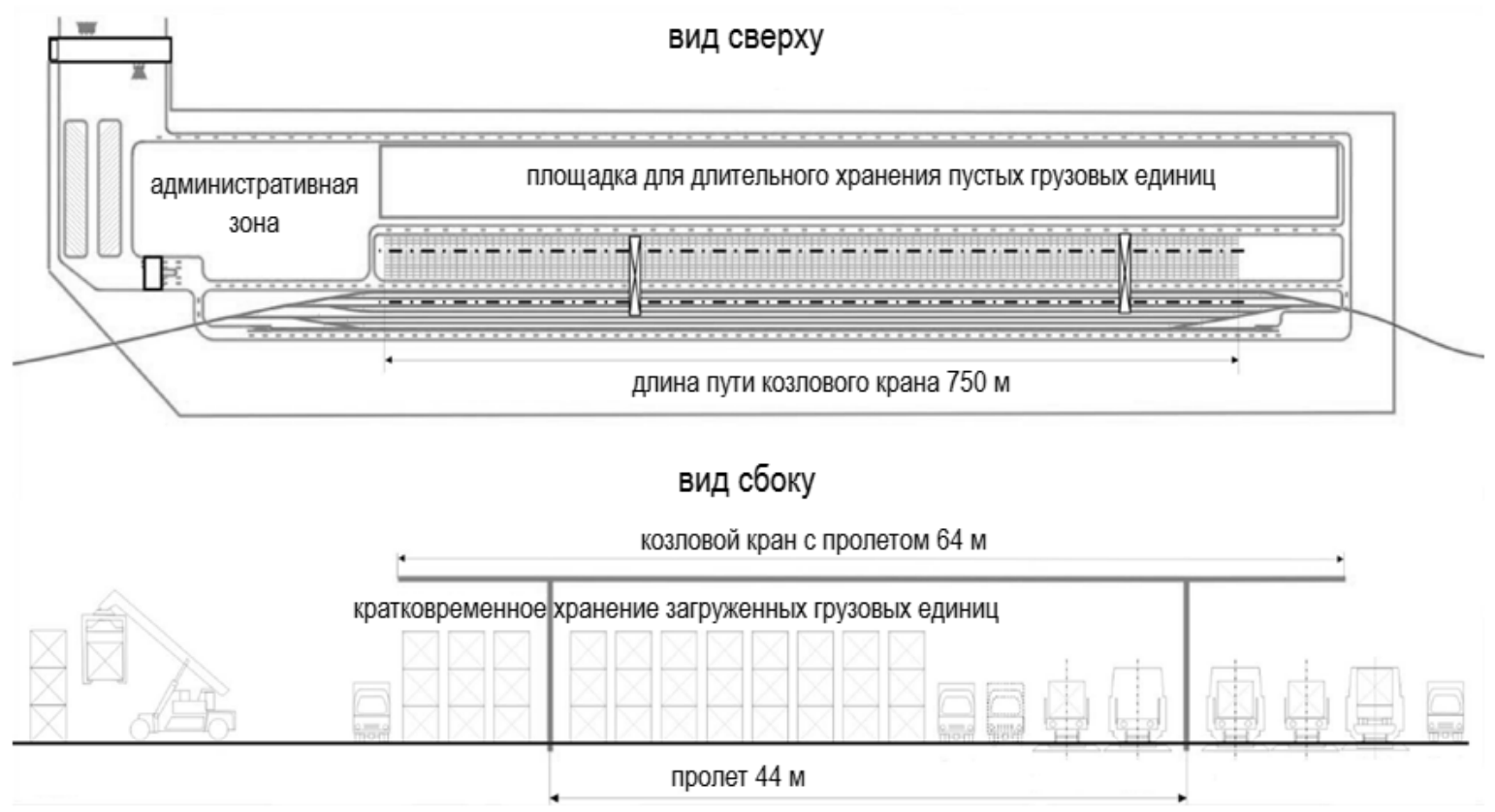

Рисунок 1 - Схема грузового транспортного узла

Основные элементы транспортного процесса называются фразами и включают погрузку, транспортировку и разгрузку. В зависимости от сложности транспортного процесса включаются дополнительные операции, такие как подготовка груза к перевозке, складирование, прием груза и обработка взаимодействующих транспортных средств, а также действия, связанные с экспедиторским обслуживанием. Крайне важно, чтобы реализация транспортного процесса строго соответствовала конкретной технологии. Комплексный процесс перевозки должен состоять из следующих технологических процессов:

- временное хранение груза в транспортных узлах;

- выполнение погрузочных операций на каждом этапе перевозки;

- перевозка грузов различными видами транспорта.

Правильная организация технологических процессов включает незамедлительное выполнение операций без временного разрыва. Для достижения этой цели необходимо контролировать подпроцессы, которые осуществляются с работающими транспортными средствами. Кроме того, важно координировать действия всех соответствующих заинтересованных сторон в процессе перевоз- 
ки, в том числе, как отправителя, так и получателя. Общая продолжительность транспортного процесса зависит от различных факторов, таких как: средняя дальность грузоперевозок; местоположение транспортных узлов на обслуживаемой территории; условия перевозки грузов; грузоподъемность и вместимость транспортного средства; техническая скорость движения; уровень механизации погрузо-разгрузочных работ [3].

Пропускная способность ТУ позволяет обрабатывать большой грузопоток, а рост объема перевозок создает постоянную потребность в оптимальном использовании ресурсов, что позволит снизить эксплуатационные расходы и время обработки грузовых единиц [1]. Следует подчеркнуть, что эффрективность перевозки зависит от организации погрузочно-разгрузочных процессов, осуществляемых в точках консолидации сети (рисунок 2), поскольку время и стоимость выполнения грузовых операций на одну единицу товара являются наибольшими.

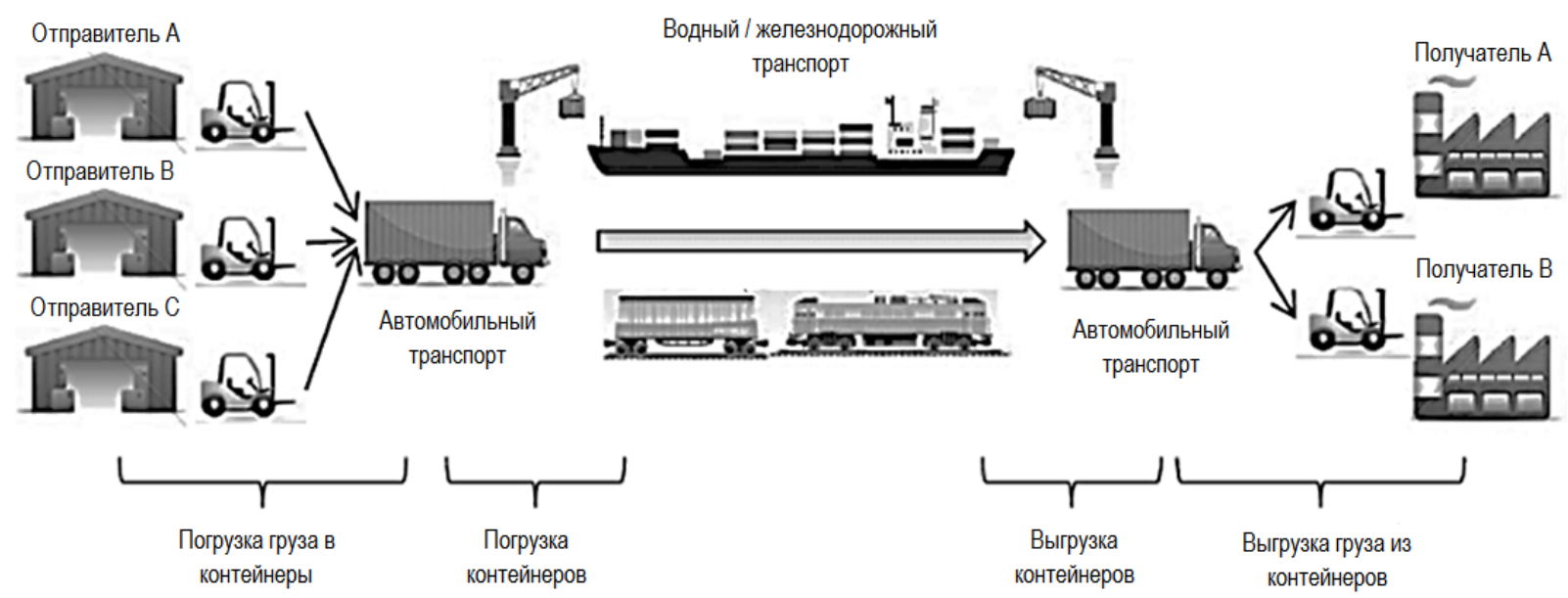

Рисунок 2 - Операции погрузки и разгрузки в точках консолидации в интермодальной транспортной сети [3]

Целью исследования является оптимизация очередности погрузкиразгрузки подвижного состава в транспортных узлах на основе критерия оптимальности. Предмет исследования - процессы погрузочно-разгрузочных работ с учетом временных и стоимостных затрат.

Ввиду неравномерности прибытия подвижного состава в транспортные узлы образуются очереди на обслуживание. При этом необходимо определить очередность обслуживания, чтобы затраты на простои транспортных средств были минимальны [4]:

$$
\sum K_{o p t}=\sum_{i=1}^{n} C_{i} \cdot t_{\text {wait }} \rightarrow \min ,
$$

где $K_{\text {opt }}$ - критерий оптимальности; $C_{i}$ - стоимость одного часа простоя $i$-го транспортного средства, руб.; $t_{\text {wait }}$ - продолжительность простоя с учетом ожи- 
дания обслуживания $i$-го транспортного средства, ч; $n$ - количество транспортных средств.

При этом число вариантов $z$ очередности обслуживания $n$ количества подвижного состава будет равно числу перестановок из $n$ элементов по $n$, то есть $z=n !$. Таким образом, при очереди из пяти транспортных средств количество вариантов будет равно 120, из шести - 720 вариантов.

Однако из множества вариантов имеется один оптимальный, который обеспечит минимальные затраты на обслуживание подвижного состава в транспортном узле. Этот вариант определяется путем ранжирования коэффиициентов приоритета $K_{p}$ в порядке убывания. Коэффрициент определяется отношением стоимостных затрат одного часа простоя к продолжительности обслуживания транспортного средства:

$$
K_{p}=\frac{C_{i}}{t_{H i}}
$$

где $t_{H i}$ - норма продолжительности обслуживания $i$-го транспортного средства, 4 .

Рассмотрим условный пример определения очередности обслуживания транспортных средств. Исходные данные для расчета сведены в таблицу 1.

Таблица 1

Исходные данные

\begin{tabular}{|c|c|c|c|}
\hline $\begin{array}{c}\text { Номер транс- } \\
\text { портного сред- } \\
\text { ства }\end{array}$ & $\begin{array}{c}\text { Вид грузовой опера- } \\
\text { ции }\end{array}$ & $\begin{array}{c}\text { Стоимость простоя, } \\
\text { руб/ч }\end{array}$ & $\begin{array}{c}\text { Норма продолжитель- } \\
\text { ности обслуживания, ч }\end{array}$ \\
\hline 1 & \multirow{2}{*}{ погрузка со склада } & 326,63 & 3,8 \\
\cline { 3 - 4 } & \multirow{2}{*}{ выгрузка на склад } & 501,50 & 5,3 \\
\cline { 3 - 4 } & & 160,25 & 1,3 \\
\hline 3 & 432,76 & 4,8 \\
\hline 4
\end{tabular}

В данном примере возможны 24 варианта очередности обслуживания. Определим очередность обслуживания с помощью коэффициентов приоритета (оптимальный вариант), а в качестве примера из множества неоптимальных рассмотрим очередность последовательности убывания стоимости простоя: транспортное средство №2 - транспортное средство №4 - транспортное средство №1 - транспортное средство №3 (расчетные значения представлены в таблице 2). 
Таблица 2

Расчетные значения по двум вариантам очередности обслуживания

\begin{tabular}{|c|c|c|c|c|}
\hline $\begin{array}{c}\text { Номер транс- } \\
\text { портного } \\
\text { средства }\end{array}$ & $\begin{array}{c}\text { Коэфффициент } \\
\text { приоритета, } \\
K_{p}\end{array}$ & $\begin{array}{l}\text { Очередность } \\
\text { обслуживания }\end{array}$ & $\begin{array}{c}\text { Продолжительность } \\
\text { ожидания, ч }\end{array}$ & $\begin{array}{l}\text { Критерий оп- } \\
\text { тимальности }\end{array}$ \\
\hline \multicolumn{5}{|c|}{ а) оптимальный вариант } \\
\hline 1 & 85,96 & 3 & 1,3 & 208,33 \\
\hline 2 & 94,62 & 2 & 6,6 & 3309,90 \\
\hline 3 & 158,65 & 4 & 11,4 & 4933,46 \\
\hline 4 & 90,16 & 1 & 15,2 & 4964,78 \\
\hline & & & & $\Sigma K_{o p t}=13416,47$ \\
\hline \multicolumn{5}{|c|}{ б) неоптимальный вариант } \\
\hline 1 & - & 2 & 5,3 & 2657,95 \\
\hline 2 & - & 4 & 10,1 & 4370,88 \\
\hline 3 & - & 1 & 13,9 & 4540,16 \\
\hline 4 & - & 3 & 15,2 & 2435,8 \\
\hline \multicolumn{5}{|r|}{$\Sigma K_{o p t}=14004,79$} \\
\hline
\end{tabular}

Таким образом, при выборе оптимального варианта обслуживания (а) суммарные затраты сократятся на 4,2 \%. Рассмотренная методика позволит повысить качество решений, относительно выбора соответствующей технологии, оборудования и систем, осуществляющих перевалку грузов.

Реализация соответствующей очередности выполнения перевалочного процесса и координация движения средств механизированной погрузкивыгрузки напрямую влияют на повышение эффективности транспортировки продукции в логистической цепи.

\section{ЛИТЕРАТУРА}

1. Гозбенко В.Е., Иванков А.Н., Колесник М.Н., Пашкова А.С. Методы прогнозирования и оптимизации транспортной сети с учетом мощности пассажиро и грузопотоков // Депонированная рукопись № 330-В2008 17.04.2008

2. Казимиров А.О., Михайлов А.Ю. Задачи территориального размещения логистической инфраструктуры в городах // В сборнике: АВИАМАШИНОСТРОЕНИЕ И ТРАНСПОРТ СИБИРИ. Сборник статей IX Всероссийской научнопрактической конференции. Иркутский национальный исследовательский технический университет; Редакционная коллегия: Бобарика И.О. (ответственный редактор); Лыткина А.А.. 2017. С. 351-355.

3. Burdzik R., Cieśla M., Sładkowski A. Cargo Loading and Unloading Efficiency Analysis in Multimodal Transport // Promet - Traffic\&Transportation, Vol. 26, 2014, No. 4, pp. 323-331.

4. Куликов Ю.И. Автомобильный транспорт в транспортной системе России: учеб. пособие / Ю.И. Куликов. - Хабаровск: Изд-во Тихоокеан. гос. ун-та, 2007. -246 c. 